\title{
Cancer Informatics: A Powerful Approach to Cancer Research in the Post- Genomic Age
}

\author{
Wang $\mathrm{X}^{*}$ \\ Department of Genetics, Cell Biology and Anatomy, University of Nebraska Medical Center, Omaha, USA
}

*Corresponding author: Wang X, Department of Genetics, Cell Biology and Anatomy, University of Nebraska Medical Center, Omaha, NE 68198-5805, USA, E-mail: xiaosheng.wang@unmc.edu

Citation: Wang X (2014) Cancer informatics: a powerful approach to cancer research in the post-genomic age. SAJ Cancer Sci 1: 104. doi: 10.18875/2375-6683.1.104

Article history: Received: 18 June 2014, Accepted: 02 September 2015, Published: 04 September 2014

Traditionally, the cancer biology has been an experimental science. However, with the advent of post-genomic age, the trend is shifting. The informatics approach is playing an increasingly important role in cancer research. In fact, a huge amount of cancer genomic data has emerged with rapid advances in genome technology. Since the end of 1990s, the microarray technology has been used to rapidly measure the expression levels of tens of thousands of genes in a single experiment [1]. This technology has facilitated the molecular exploration of cancer [2-9]. For example, for medical applications, microarray gene expression profiling has been used to develop classifiers of prognosis or sensitivity to particular treatments [10-15].

One of the most successful story of application of microarray gene expression profiling for cancer research was the molecular classification of breast cancer [16]. The gene expression profiles based signatures such as the Agendia Symphony Breast Cancer Decision Suite (TargetPrint, MammaPrint, BluePrint, and TheraPrint) have been widely used for estimating the recurrence risk, and guiding targeted treatment of breast cancer [17]. Notably, the cancer informatics approach has played an important role in identification of the gene expression signatures [18].

Since the mid-2000s, the next-generation sequencing (NGS) technology has achieved amazing progress [19]. Currently, the NGS technology is capable of sequencing a large number of DNA/RNA samples in parallel at a reasonable expense that makes it to become a state-of-the-art tool for cancer research. Although the large size of NGS reads are imposing big challenges for the informatics approach to data transfer, storage, quality control, and analysis [19,20], they are making detection and application of mutant biomarkers for cancer a reality. So far, a large amount of NGS data on cancer genomes has emerged such as The Cancer Genome Atlas (TCGA) [20], International Cancer Genome Consortium (ICGC) [21], and the Cancer Genome Project (CGP) [22]. The cancer genome data may allow oncologists to identify the specific mutations a cancer patient has, based on which a personalized therapeutic strategy can be undertaken [23]. In this process, the bioinformatics approach plays a crucial role in detection of mutant genes, development of predictive models, inference of tumor progress and metastasis, and screening of drug targets.

In conclusion, cancer informatics has become an increasingly important approach to cancer research in the post-genomic age. The conquest of cancer might largely depend on the breakthrough of cancer informatics techniques.

\section{References}

1. Schena M, Shalon D, Davis RW, Brown PO (1995) Quantitative monitoring of gene expression patterns with a complementary DNA microarray. Science 270: 467-70.

2. Golub TR, Slonim DK, Tamayo P, Huard C, Gaasenbeek M, et al. (1999) Molecular classification of cancer: class discovery and class prediction by gene expression monitoring. Science 286: 531-7.

3. Gordon GJ, Jensen RV, Hsiao LL, Gullans SR, Blumenstock JE, et al. (2002) Translation of microarray data into clinically relevant cancer diagnostic tests using gene expression ratios in lung cancer and mesothelioma. Cancer Res 62: 4963-7.

4. Gordon GJ, Jensen RV, Hsiao LL, Gullans SR, Blumenstock JE, et al. (2003) Using gene expression ratios to predict outcome among patients with mesothelioma. J Natl Cancer Inst 95: 598-605.

5. van 't Veer LJ, Dai H, van de Vijver MJ, He YD, Hart AA, et al. (2002) Gene expression profiling predicts clinical outcome of breast cancer. Nature 415: 530-6.

6. Singh D, Febbo PG, Ross K, Jackson DG, Manola J, et al. (2002) Gene expression correlates of clinical prostate cancer behavior. Cancer Cell 1: 203-9.

7. Pomeroy SL, Tamayo P, Gaasenbeek M, Sturla LM, Angelo M, et al. (2002) Prediction of central nervous system embryonal tumour outcome based on gene expression. Nature 415: 436-42. 
8. Shipp MA, Ross KN, Tamayo P, Weng AP, Kutok JL, et al. (2002) Diffuse large B-cell lymphoma outcome prediction by gene-expression profiling and supervised machine learning. Nat Med 8: 68-74.

9. Liotta L, Petricoin E (2000) Molecular profiling of human cancer. Nat Rev Genet 1: 48-56.

10. Wang X, Simon R (2011) Microarray-based cancer prediction using single genes. BMC Bioinformatics 12: 391.

11. Wang X (2012) Robust two-gene classifiers for cancer prediction. Genomics 99: 90-5.

12. Wang X, Gotoh O (2009) Accurate molecular classification of cancer using simple rules. BMC Med Genomics 2: 64.

13. Wang X, Gotoh O (2010) A robust gene selection method for microarray-based cancer classification. Cancer Inform 9: 15-30.

14. Wang X, Gotoh O (2009) Microarray-based cancer prediction using soft computing approach. Cancer Inform 7: $123-39$.

15. Wang X (2014) Identification of Marker Genes for Cancer Based on Microarrays Using a Computational Biology Approach. Current Bioinformatics 9: 140-6.

16. Polyak K (2011) Heterogeneity in breast cancer. J Clin Invest 121: 3786-8.

17. Agendia decoding cancer. USA.

18. de Snoo F, Bender R, Glas A, Rutgers E (2009) Gene expression profiling: decoding breast cancer. Surg Oncol 18: 366-78.

19. Metzker ML (2010) Sequencing technologies - the next generation. Nat Rev Genet 11:31-46.

20. TCGA Data Portal Overview- The National Cancer Genome Atlas. National Cancer Institute, Maryland, USA.

21. International Cancer Genome Consortium.

22. Cancer genome project-Wellcome trust Sanger institute. Cambridge, UK.

23. Roychowdhury S, Iyer MK, Robinson DR, Lonigro RJ, Wu YM, et al. (2011) Personalized oncology through integrative high-throughput sequencing: a pilot study. Sci Transl Med 3: 111 ra121. 